\title{
Differences between patient- and professional-reported modified Rankin Scale score in patients with unruptured aneurysms
}

\author{
Lorenzo Rinaldo, MD, PhD, ${ }^{1}$ Diane M. Johnson, RN, ${ }^{1}$ Roanna L. Vine, RN, ${ }^{2}$ \\ Alejandro A. Rabinstein, MD, ${ }^{3}$ and Giuseppe Lanzino, MD ${ }^{1,2}$ \\ Departments of ${ }^{1}$ Neurosurgery, ${ }^{2}$ Radiology, and ${ }^{3}$ Neurology, Mayo Clinic, Rochester, Minnesota
}

OBJECTIVE Clinical trials forming the basis of current guidelines for the management of intracranial aneurysms have relied on patient-reported modified Rankin Scale (mRS) scores to assess functional outcome. The effect of patient demographics on perception of disability and, by extension, patient-reported mRS score, is not well understood.

METHODS A consecutive series of patients with a previously treated or untreated unruptured intracranial aneurysm (UIA) prospectively underwent a structured interview with a trained nurse. At the conclusion of this interview, the patients were assigned an $\mathrm{mRS}$ score in accordance with their degree of disability. During the same visit, patients were also required to grade themselves on a paper sheet containing the mRS and corresponding information. Data on patient and aneurysm characteristics were also collected during the same visit. Agreement between patient- and nurse-reported mRS scores was assessed using Cohen's kappa coefficient. The effect of patient demographics on the frequency of higher patient- than nurse-reported mRS scores was assessed using the Pearson's chi-square and Fisher's exact tests.

RESULTS A total of 209 patients with a UIA were included in the study, 38 of whom (18.2\%) had undergone previous treatment. The majority of patients were female $(161 / 209,77.0 \%)$, and the mean age of the cohort was 60.2 years (SD 13.7 years). Agreement between patient- and nurse-reported mRS scores occurred in $72.7 \%$ of cases $(95 \% \mathrm{Cl} 66.3 \%$ $78.3 \%)$, with a kappa coefficient of $0.58(95 \% \mathrm{Cl} 0.49-0.67)$. Patients younger than 75 years were more likely to report a higher $\mathrm{mRS}$ score than the nurse $(19.4 \%$ vs $3.4 \%, \mathrm{p}=0.034)$. Among female patients, those without a college degree were more likely to report a higher mRS score than the nurse $(22.5 \%$ vs $9.5 \%, p=0.035)$.

CONCLUSIONS The results suggest that patient demographics may influence perception of disability. These findings should be considered when using patient-reported mRS scores to determine functional outcome.

https://thejns.org/doi/abs/10.3171/2018.3.JNS18247

KEYWORDS education; intracranial aneurysm; patient-reported outcome measures; vascular disorders

$\mathrm{T}$ HE contemporary need to improve the value of healthcare delivery has driven increasing interest in the use of patient-reported outcomes (PROs) to assess the efficacy of both medical and surgical interventions. ${ }^{9,15}$ In the International Subarachnoid Hemorrhage Trial (ISAT), for the first time in a clinical trial assessing outcome after subarachnoid hemorrhage, functional outcome was based not on a third-party assessment but rather on patients' self-assessments of their disability as defined by the modified Rankin Scale (mRS). ${ }^{10}$ While the use of PROs is important for the delivery of patient-centered care, patient perception of the severity of their illness may be influenced by factors unrelated to objective neurological disability. ${ }^{4,14}$ Moreover, there is little information on the effect of basic patient characteristics, such as age, sex, and education level, on perception of disability and therefore self-assigned score on the mRS. We compared patient- and nurse-reported mRS scores in a consecutive, prospective

ABBREVIATIONS mRS = modified Rankin Scale; PRO = patient-reported outcome; UIA = unruptured intracranial aneurysm.

SUBMITTED January 29, 2018. ACCEPTED March 6, 2018.

INCLUDE WHEN CITING Published online August 10, 2018; DOI: 10.3171/2018.3.JNS18247. 
series of patients with an unruptured intracranial aneurysm (UIA) to determine whether patient characteristics influence patient perception of disability.

\section{Methods \\ Determination of Patient- and Nurse-Reported mRS Scores}

After approval from our institutional review board was granted, consecutive patients presenting to a single neurosurgeon (G.L.) between 2012 and 2014 for management of either a previously treated or untreated UIA were prospectively included in the study. Patients with a coexisting physical impairment causing obvious physical disability were excluded from the study. Patients first underwent a structured interview by a trained nurse (D.M.J.) certified to ascertain patient disability according to the mRS. Interviews were conducted in person and were approximately 10 to 15 minutes in duration. At the conclusion of the interview, patients were assigned an $\mathrm{mRS}$ score based on the nurse's assessment of their degree of disability. Patients, who were blinded to the nurse's assessment, were subsequently instructed to assign themselves a score on the $\mathrm{mRS}$ with the aid of a standard form providing definitions of the mRS scores (www.strokecenter.org/wp-content/ uploads/2011/08/modified_rankin.pdf).

\section{Patient Outcomes and Variables of Interest}

The primary outcomes of interest were agreement between patient- and nurse-reported mRS scores and the frequency with which the patient-reported $\mathrm{mRS}$ score was higher than the nurse-reported mRS score. We also noted the incidence of patient- and nurse-reported mRS scores higher than 2. Information collected on patient characteristics included age in years at the time of assessment, sex, education level, history of aneurysm treatment, treatment modality, permanent neurological complications incurred from aneurysm treatment, time in months between aneurysm treatment and assessment for this study, history of subarachnoid hemorrhage from a different intracranial aneurysm, and time in months between previous subarachnoid hemorrhage and assessment. Patient age was considered as a categorical variable with a cutoff of 75 years or older. This cutoff was chosen through the use of classification and regression tree analysis, which, for an independent continuous variable, determines the cutoff above and below which there is the greatest difference in a dependent variable. The dependent variable in this case was the frequency with which the patient-reported $\mathrm{mRS}$ score was higher than the nurse-reported mRS score. Categories for education level were defined as less than a high school degree, high school degree, some college or 2-year degree, 4-year college degree, and postgraduate education. For the purposes of statistical analysis, patients were stratified according to whether or not they had attained a 4 -year college degree. The incidence of permanent neurological complications incurred from aneurysm treatment was determined retrospectively through review of the electronic medical record. Although information on time elapsed from previous aneurysm treatment or subarachnoid hemorrhage from a different intracranial aneurysm and inclusion in the present study was collected, accurate information on time from aneurysm diagnosis to study inclusion was unavailable for a majority of patients with untreated aneurysms and no history of subarachnoid hemorrhage. In general, patients fitting this description were referred to our institution for neurological and neurosurgical consultation within 2 to 3 weeks of initial diagnosis, at which time they were enrolled in this study.

\section{Statistical Analysis}

Descriptive statistics are presented as the mean, standard deviation, and range for continuous variables and frequency and percentage for categorical variables. Agreement between patient- and nurse-reported mRS scores was quantified with raw agreement rates as well as Cohen's kappa coefficient. Categorical variables were compared using the Pearson's chi-square test or Fisher's exact test, where appropriate. Given the association of multiple patient characteristics with higher patient- than nursereported mRS scores among female patients, variables significantly associated with higher patient- than nursereported $\mathrm{mRS}$ scores on univariate analysis were included in a multivariate logistic regression model. An odds ratio could not be calculated for the variable of age, given the absence of female patients 75 years or older who reported a higher patient- than nurse-reported mRS score; the $p$ value for this variable was reported as the result of an effect likelihood-ratio test. All statistical tests were 2-sided with an alpha level set at 0.05 for statistical significance. Analyses were performed using commercially available software (JMP 10.0.0, 2012, SAS Institute Inc.).

\section{Results}

\section{Patient Characteristics}

A total of 209 patients met the inclusion criteria of our study. The mean age of the cohort was 60.2 years (SD 13.7 years), and the majority of patients were female (161/209, $77.0 \%$ ). There were 38 patients who had previously undergone treatment of their UIA. A large majority of patients were treated via endovascular means $(37 / 38,97.4 \%)$, with only a single patient treated with surgical clipping (2.6\%). Of the patients treated endovascularly, 27 (73.0\%) were treated with coil embolization, and 10 were treated with flow diversion (27.0\%). Only 1 patient sustained treatmentrelated permanent neurological morbidity (2.6\%). The mean time between aneurysm treatment and study inclusion was 36.8 months (SD 36.6 months, range 1.1-150.6 months). Eight patients had a history of subarachnoid hemorrhage from a different intracranial aneurysm (Table 1). The mean time between previous subarachnoid hemorrhage and study inclusion was 102.3 months (SD 74.9 months, range 18.3-237.7 months).

\section{Agreement Between Patient- and Nurse-Reported mRS Scores}

The distribution of patient- and nurse-reported mRS scores is depicted in Table 1 and Fig. 1. There were 17 patients who assigned themselves an mRS score higher than 2 , while there were only 3 instances of a nurse-reported score higher than 2, yielding 14 (6.7\%) patients with a self- 
TABLE 1. Patient characteristics

\begin{tabular}{|c|c|}
\hline & Value \\
\hline No. of patients & 209 \\
\hline \multicolumn{2}{|l|}{ Age, yrs } \\
\hline Mean (SD) & $60.2(13.7)$ \\
\hline Range & $20-88$ \\
\hline \multicolumn{2}{|l|}{ Sex } \\
\hline Male & $48(23.0)$ \\
\hline Female & $161(77.0)$ \\
\hline \multicolumn{2}{|l|}{ 4-yr college degree } \\
\hline No & $131(62.7)$ \\
\hline Yes & $78(37.3)$ \\
\hline \multicolumn{2}{|l|}{ Previously treated } \\
\hline No & $171(81.8)$ \\
\hline Yes & $38(18.2)$ \\
\hline \multicolumn{2}{|l|}{ Complications from treatment ${ }^{*}$} \\
\hline No & $37(97.4)$ \\
\hline Yes & $1(2.6)$ \\
\hline \multicolumn{2}{|l|}{ Previous SAH } \\
\hline No & $201(96.2)$ \\
\hline Yes & $8(3.8)$ \\
\hline \multicolumn{2}{|l|}{ Patient-reported mRS score } \\
\hline 0 & $39(18.7)$ \\
\hline 1 & $93(44.5)$ \\
\hline 2 & $60(28.7)$ \\
\hline 3 & $16(7.7)$ \\
\hline 4 & $1(0.5)$ \\
\hline \multicolumn{2}{|l|}{ Nurse-reported mRS score } \\
\hline 0 & $30(14.4)$ \\
\hline 1 & $112(53.6)$ \\
\hline 2 & $64(30.6)$ \\
\hline 3 & $3(1.4)$ \\
\hline Patient-reported mRS score >2 & $17(8.1)$ \\
\hline Nurse-reported mRS score >2 & $3(1.4)$ \\
\hline
\end{tabular}

$\mathrm{SAH}=$ subarachnoid hemorrhage.

Values are presented as the number of patients (\%) unless stated otherwise.

* Noted only for treated aneurysms.

reported score higher than 2 and a nurse-reported score of lower than or equal to 2 . Overall, agreement between patient- and nurse-reported mRS scores occurred in $72.7 \%$ of cases (95\% CI 66.3\%-78.3\%). The rates of agreement for different patient groups are summarized in Table 2. The kappa coefficient for agreement between patient- and nurse-reported mRS scores was 0.58 (95\% CI 0.49-0.67), with the kappa coefficient for different patient groups also provided in Table 2.

There were 36 patients (17.2\%) who assigned themselves an mRS score higher than that assigned to them by the nurse. Patients 75 years or older were less likely to assign themselves a higher mRS score than the nurse (3.4\% vs $19.4 \%, \mathrm{p}=0.034)$. Among female patients, those without a college degree were more likely to assign themselves a higher mRS score than patients with a college

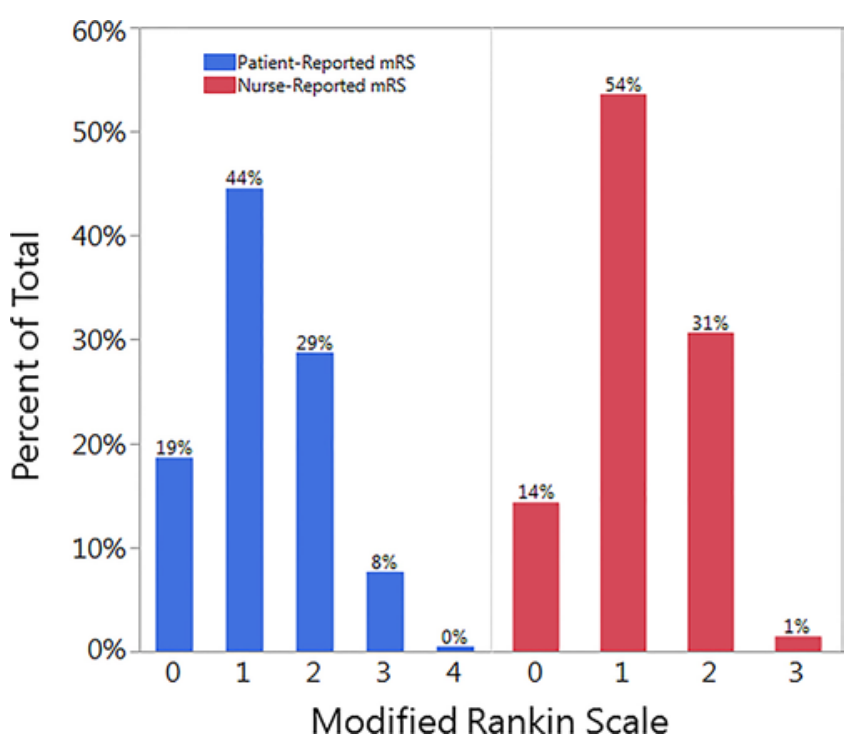

FIG. 1. Distribution of patient- and nurse-reported mRS scores. Figure is available in color online only.

degree $(22.5 \%$ vs $9.5 \%, \mathrm{p}=0.035)$. Patients 75 or older were also less likely to assign themselves a higher patientthan nurse-reported mRS score compared with younger patients when the analysis was limited to female patients (0.0\% vs $19.9 \%, p=0.026)$. The complete results of the effect of patient demographics on the incidence of higher patient- than nurse-reported mRS scores are summarized in Table 3. To assess for independent predictors of higher patient- than nurse-reported mRS scores among female patients, patient age and education level were included in a multivariate logistic regression model. Attainment of a college degree (OR 0.32, 95\% CI 0.12-0.85; $\mathrm{p}=0.022$ ) and age 75 years or older $(\mathrm{p}=0.002)$ were independently associated with a reduced likelihood of having higher patient- than nurse-reported mRS scores (Table 4).

\section{Discussion}

In this prospective study of a consecutive series of patients presenting with a UIA, we provide evidence that basic patient characteristics, such as age and education level, may influence patients' perceptions of their level of disability, leading to a discrepancy with the degree of disability ascribed to them by a trained professional. These results may have implications for the assessment of outcome using the mRS in patients with intracranial aneurysms.

Elderly patients were less likely than younger patients to assign themselves a higher mRS score than that assigned by the nurse. There is evidence to suggest that as patients age, personal valuation of functional impairment is determined more by the degree to which an illness affects a patient's independence as opposed to the clinical manifestations of that illness, for example, pain. ${ }^{7}$ Due to the significance placed on functional independence in this population, elderly patients may have a higher threshold for assigning themselves higher values on the mRS relative to their younger counterparts, particularly given how different scores of the mRS are defined. ${ }^{2}$ Further investi- 
TABLE 2. Agreement between patient- and nurse-reported mRS scores

\begin{tabular}{|c|c|c|c|c|}
\hline Variable & Agreement & $95 \% \mathrm{Cl}$ & Kappa Coefficient & $95 \% \mathrm{Cl}$ \\
\hline All patients & $72.7 \%$ & 66.3 to $78.3 \%$ & 0.58 & 0.49 to 0.67 \\
\hline \multicolumn{5}{|l|}{ Age $\geq 75$ yrs } \\
\hline No & $73.3 \%$ & 66.4 to $79.3 \%$ & 0.59 & 0.49 to 0.69 \\
\hline Yes & $69.0 \%$ & 50.8 to $82.7 \%$ & 0.50 & 0.25 to 0.76 \\
\hline \multicolumn{5}{|l|}{ Sex } \\
\hline Male & $64.6 \%$ & 50.4 to $76.6 \%$ & 0.42 & 0.21 to 0.63 \\
\hline Female & $75.2 \%$ & 67.9 to $81.2 \%$ & 0.62 & 0.52 to 0.72 \\
\hline \multicolumn{5}{|l|}{ 4-yr college degree } \\
\hline No & $70.2 \%$ & 61.9 to $77.3 \%$ & 0.55 & 0.44 to 0.67 \\
\hline Yes & $76.9 \%$ & 66.4 to $84.9 \%$ & 0.62 & 0.47 to 0.77 \\
\hline \multicolumn{5}{|c|}{ Female w/ 4-yr college degree* } \\
\hline No & $69.4 \%$ & 59.7 to $77.6 \%$ & 0.54 & 0.41 to 0.68 \\
\hline Yes & $84.1 \%$ & 73.2 to $91.1 \%$ & 0.74 & 0.59 to 0.88 \\
\hline \multicolumn{5}{|c|}{ Male w/ 4-yr college degree* } \\
\hline No & $72.7 \%$ & 55.8 to $84.9 \%$ & 0.55 & 0.31 to 0.79 \\
\hline Yes & $46.7 \%$ & 24.8 to $70.0 \%$ & 0.13 & -0.23 to 0.50 \\
\hline \multicolumn{5}{|l|}{ Previously treated } \\
\hline No & $73.1 \%$ & 66.0 to $79.2 \%$ & 0.58 & 0.48 to 0.68 \\
\hline Yes & $71.1 \%$ & 55.2 to $83.0 \%$ & 0.55 & 0.33 to 0.77 \\
\hline \multicolumn{5}{|l|}{ Previous SAH } \\
\hline No & $72.1 \%$ & 65.6 to $77.9 \%$ & 0.57 & 0.47 to 0.66 \\
\hline Yes & $87.5 \%$ & 52.9 to $97.8 \%$ & 0.78 & 0.42 to 1.00 \\
\hline
\end{tabular}

* Opposite sex excluded from analysis.

gation into the effect of age on perception of disability is warranted.

Our findings suggest that a heightened sense of disability may be more likely in female patients with lower levels of education (Table 3). Though not a perfect surrogate, education level is a marker of socioeconomic status, ${ }^{6,12}$ which has consistently been correlated to personal opinions of health status. ${ }^{1,5}$ It is unclear, however, why an effect of education level was seen only in female patients. The mechanism by which the interplay between patient sex and education level influences patient perception of disability is likely to be complex and warrants further investigation. Regardless, while these findings may help explain poor self-reported outcomes in the absence of significant neurological disability, they are perhaps most important in that they may aid in the early identification of patients at high risk for an unsatisfactory outcome, and those who may be more likely to benefit from a multimodal approach to patient care.

Our study inevitably raises the question of how best to assess functional outcome in patients with intracranial aneurysms. We would argue against the elimination of PROs. Recovery after treatment of an intracranial aneurysm is a multifactorial process, $, 3,13$ and physician or nurse assessments focused exclusively on objective neurological disability are unlikely to provide a comprehensive view of a patient's level of functioning and well-being. ${ }^{8}$ On the other hand, our findings suggest that the use of patientreported mRS scores may result in overestimation of physical impairment in certain patient groups. In addition, previous studies have also shown that the mRS score correlates poorly with validated measures of personal health, ${ }^{8}$ implying that patients with differing perceptions of personal health may rate themselves similarly on the mRS, raising questions about the real-life significance of patient outcomes assessed with this tool. More sophisticated outcome measures, for example, instruments that account for patient age, sex, and education level, may be required for patients with intracranial aneurysms. In the meantime, when assessing outcome in patients with intracranial aneurysms, consideration of how patient characteristics may influence patient-reported mRS scores should be taken into account.

\section{Limitations}

Our study is limited by its single-center design. Our institution serves a predominantly Caucasian population, and thus our results may not be generalizable to minority patient populations or patients in other geographic locations. The fact that all professional assessments were made by a single nurse could have introduced an unintentional bias. Nevertheless, the study was prospective and included a large, modern consecutive cohort of patients.

Among patients with aneurysms that were previously treated, only a single patient was treated with surgical clipping, and thus our results may not be generalizable to all patients with a previously treated unruptured aneu- 
TABLE 3. Factors associated with higher patient- than nursereported $m R S$ scores

\begin{tabular}{|c|c|c|c|}
\hline Variable & $\begin{array}{c}\text { Patient mRS } \\
\text { Score } \leq \text { Nurse } \\
\text { mRS Score }\end{array}$ & $\begin{array}{c}\text { Patient mRS } \\
\text { Score > Nurse } \\
\text { mRS Score }\end{array}$ & $\begin{array}{c}\mathrm{p} \\
\text { Value }\end{array}$ \\
\hline All patients, n (\%) & $173(82.8)$ & $36(17.2)$ & \\
\hline Age $\geq 75$ yrs & & & $0.034^{*}$ \\
\hline No & $145(80.6)$ & $35(19.4)$ & \\
\hline Yes & $28(96.6)$ & $1(3.4)$ & \\
\hline Females $\geq 75$ yrs $\dagger$ & & & $0.026^{*}$ \\
\hline No & $113(80.1)$ & $28(19.9)$ & \\
\hline Yes & $20(100.0)$ & $0(0.0)$ & \\
\hline Sex & & & 0.907 \\
\hline Male & $40(83.3)$ & $8(16.7)$ & \\
\hline Female & $133(82.6)$ & $28(17.4)$ & \\
\hline 4-yr college degree & & & 0.193 \\
\hline No & $105(80.2)$ & $26(19.8)$ & \\
\hline Yes & $68(87.2)$ & $10(12.8)$ & \\
\hline $\begin{array}{l}\text { Female w/ 4-yr college } \\
\text { degree } †\end{array}$ & & & 0.035 \\
\hline No & $76(77.5)$ & $22(22.5)$ & \\
\hline Yes & $57(90.5)$ & $6(9.5)$ & \\
\hline $\begin{array}{l}\text { Male with 4-yr college } \\
\text { degree† }\end{array}$ & & & $0.236^{*}$ \\
\hline No & $29(87.9)$ & $4(12.1)$ & \\
\hline Yes & $11(73.3)$ & $4(26.7)$ & \\
\hline Previously treated & & & 0.796 \\
\hline No & $141(82.5)$ & $30(17.5)$ & \\
\hline Yes & $32(84.2)$ & $6(15.8)$ & \\
\hline Previous SAH & & & 0.796 \\
\hline No & $165(82.1)$ & $36(17.9)$ & \\
\hline Yes & $8(100.0)$ & $0(0.0)$ & \\
\hline
\end{tabular}

Boldface type indicates statistical significance.

${ }^{*}$ Calculated using Fisher's exact test.

† Opposite sex excluded from analysis.

rysm. There were differences in time from aneurysm diagnosis to study inclusion between patients with a history of aneurysm treatment or subarachnoid hemorrhage and those with untreated aneurysms and no history of subarachnoid hemorrhage. Patients in the former group were enrolled on average 36.8 and 102.3 months after treatment or subarachnoid hemorrhage, respectively, and a majority of the latter group was enrolled within 2 to 3 weeks of initial diagnosis. While the effect of time on perception of disability is not well understood and likely quite variable, it is possible that differences in time from aneurysm diagnosis to $\mathrm{mRS}$ assessment may have affected comparisons between groups. Overall, the primary intention of this study was to determine whether differences existed between patient- and nurse-reported mRS scores, regardless of aneurysm treatment status. Future studies will specifically aim to determine whether these differences are more pronounced in patients with treated versus untreated aneurysms.
TABLE 4. Multivariate logistic regression analysis indicating predictors of higher patient- than nurse-reported $\mathrm{mRS}$ scores among female patients

\begin{tabular}{|c|c|c|}
\hline Variable & OR $(95 \% \mathrm{Cl})$ & $p$ Value \\
\hline Age $\geq 75$ & $N A^{*}$ & $0.002 \dagger$ \\
\hline 4-yr college degree & $0.32(0.12-0.85)$ & 0.022 \\
\hline \multicolumn{3}{|c|}{$\begin{array}{l}\text { NA = not applicable. } \\
\text { Boldface type indicates statistical significance. } \\
\text { *An odds ratio could not be calculated as no female patients } 75 \text { years or olde } \\
\text { reported a higher mRS score than that reported by the nurse. } \\
\text { † Result of effect-likelihood ratio test. }\end{array}$} \\
\hline
\end{tabular}

Finally, we employed the mRS in a population in which a large majority of patients had not previously had a stroke. While there is evidence supporting the use of the $\mathrm{mRS}$ to assess functional outcome in patients with a broad range of neurosurgical conditions, ${ }^{11}$ the scale has not been as thoroughly validated in these populations. In addition, patient- and nurse-reported scores were within the range of 0 to 2 for $92 \%$ and $99 \%$ of patients, respectively (Fig. 1), a range generally considered to represent a good functional outcome, at least in previous clinical trials. ${ }^{10}$ As such, differences between patient- and nurse-reported scores within this score range may have limited clinical significance. On the other hand, there were 14 instances $(6.7 \%)$ in which patient-reported scores were higher than 2 and nurse-reported scores were lower than or equal to 2 , indicating that "clinically significant" differences between patient- and professional-reported scores can occur intermittently even in patients with minimal neurological dysfunction. Regardless, the purpose of this study was to investigate the clinical suspicion that factors other than objective neurological disability can affect patient perception regarding the effect of disease on their quality of life. Future studies will aim to quantify the effect of these factors on PROs in other populations, specifically patients recovering from subarachnoid hemorrhage.

\section{Conclusions}

While important and necessary, PROs need to be collected in conjunction with other factors that may influence patient perception of disability, especially if these measures are to be used to assess outcome after invasive procedures.

\section{References}

1. Adler NE, Ostrove JM: Socioeconomic status and health: what we know and what we don't. Ann N Y Acad Sci 896:315,1999

2. Bonita R, Beaglehole R: Recovery of motor function after stroke. Stroke 19:1497-1500, 1988

3. Buijs JE, Greebe P, Rinkel GJ: Quality of life, anxiety, and depression in patients with an unruptured intracranial aneurysm with or without aneurysm occlusion. Neurosurgery 70:868-872, 2012

4. Fontana J, Wenz R, Groden C, Schmieder K, Wenz H: The preinterventional psychiatric history as a major predictor for a reduced quality of life after treatment of unruptured intracranial aneurysms. World Neurosurg 84:1215-1222, 2015 
5. Hemingway H, Nicholson A, Stafford M, Roberts R, Marmot $\mathrm{M}$ : The impact of socioeconomic status on health functioning as assessed by the SF-36 questionnaire: the Whitehall II Study. Am J Public Health 87:1484-1490, 1997

6. Herd P, Goesling B, House JS: Socioeconomic position and health: the differential effects of education versus income on the onset versus progression of health problems. J Health Soc Behav 48:223-238, 2007

7. Hofman CS, Makai P, Boter H, Buurman BM, de Craen AJ, Olde Rikkert MG, et al: The influence of age on health valuations: the older olds prefer functional independence while the younger olds prefer less morbidity. Clin Interv Aging 10:1131-1139, 2015

8. Kim DH, Haney CL, Van Ginhoven G: Utility of outcome measures after treatment for intracranial aneurysms: a prospective trial involving 520 patients. Stroke 36:792-796, 2005

9. Kotronoulas G, Kearney N, Maguire R, Harrow A, Di Domenico D, Croy S, et al: What is the value of the routine use of patient-reported outcome measures toward improvement of patient outcomes, processes of care, and health service outcomes in cancer care? A systematic review of controlled trials. J Clin Oncol 32:1480-1501, 2014

10. Molyneux AJ, Kerr RS, Yu LM, Clarke M, Sneade M, Yarnold JA, et al: International subarachnoid aneurysm trial (ISAT) of neurosurgical clipping versus endovascular coiling in 2143 patients with ruptured intracranial aneurysms: a randomised comparison of effects on survival, dependency, seizures, rebleeding, subgroups, and aneurysm occlusion. Lancet 366:809-817, 2005

11. Patel N, Rao VA, Heilman-Espinoza ER, Lai R, Quesada RA, Flint AC: Simple and reliable determination of the modified Rankin Scale score in neurosurgical and neurological patients: the mRS-9Q. Neurosurgery 71:971-975, 2012
12. Schnittker J: Education and the changing shape of the income gradient in health. J Health Soc Behav 45:286-305, 2004

13. van der Schaaf IC, Brilstra EH, Rinkel GJ, Bossuyt PM, van Gijn J: Quality of life, anxiety, and depression in patients with an untreated intracranial aneurysm or arteriovenous malformation. Stroke 33:440-443, 2002

14. Wenz H, Wenz R, Ehrlich G, Groden C, Schmieder K, Fontana J: Patient characteristics support unfavorable psychiatric outcome after treatment of unruptured intracranial aneurysms. Acta Neurochir (Wien) 157:1135-1145, 2015

15. Wysham NG, Abernethy AP, Cox CE: Setting the vision: applied patient-reported outcomes and smart, connected digital healthcare systems to improve patient-centered outcomes prediction in critical illness. Curr Opin Crit Care 20:566572,2014

\section{Disclosures}

Dr. Lanzino: consultant for Medtronic.

\section{Author Contributions}

Conception and design: Lanzino, Rinaldo, Vine, Rabinstein. Acquisition of data: Rinaldo, Johnson. Analysis and interpretation of data: Lanzino, Rinaldo, Vine, Rabinstein. Drafting the article: Rinaldo. Critically revising the article: all authors. Reviewed submitted version of manuscript: all authors. Approved the final version of the manuscript on behalf of all authors: Lanzino. Statistical analysis: Rinaldo. Study supervision: Lanzino.

\section{Correspondence}

Giuseppe Lanzino: Mayo Clinic, Rochester, MN. lanzino. giuseppe@mayo.edu. 